\title{
Longitudinal inconsistency in responses to survey items that ask women about intimate partner violence
}

\author{
Deborah Loxton ${ }^{*} \mathbb{D}$, Jennifer Powers, Natalie Townsend, Melissa L. Harris and Peta Forder
}

\begin{abstract}
Background: Longitudinal research has demonstrated that experiences of abuse and adversity are not consistently reported over time; however, there is a paucity of available evidence regarding the consistency of reporting experiences of intimate partner violence (IPV) over time. This study aimed to investigate the consistency of selfreported IPV involving a partner or spouse. Differences in the health status of women according to consistency of IPV reporting was also investigated.

Methods: Survey data collected from the 1946-51 cohort of the Australian Longitudinal Study on Women's Health (ALSWH) between 1996 and 2016 were used $(n=13,715)$. Consistency of self-reported IPV was evaluated by responses to the question "Have you ever been in a violent relationship with a partner/spouse?" Demographic and health characteristics of consistent and inconsistent reporters of IPV were compared. Multinomial logistic regression was used to determine the strength of the association between demographic and health characteristics of the women and their consistency of longitudinal reporting of IPV.
\end{abstract}

Results: There were 10,966 women who answered IPV questions over six surveys, with 9610 women (87.6\%) providing consistent responses. Inconsistent responses were provided by 1356 women (12.4\%), of whom 258 (2.4\%) reported IPV at all but one survey (Mainly IPV), 587 (5.3\%) reported no IPV at all but one survey (Mainly no IPV), and 511 (4.7\%) reported Mixed IPV responses over time. Women in the Mainly IPV group, and those in the Mixed IPV group were similar to those in the Consistent IPV group in demographic and health characteristics, whereas women in the Mainly no IPV group were similar to those in the Consistent never IPV group.

Conclusions: IPV data collected at one time point may involve around 12\% false negative or false positive responses. To increase reliability, IPV should be measured on more than one occasion, using different techniques and methods that account for intentional and unintentional over- and under-reporting.

Keywords: Intimate partner violence, Longitudinal studies, Cohort studies, Surveys and questionnaires, Self report, Response consistency, Reliability

\section{Background}

Intimate partner violence (IPV) is a significant public health problem. Experiences of IPV have been shown to be associated with a range of physical health problems, such as breathing difficulties, asthma, emphysema, bronchitis, allergies, fatigue, low iron, vaginal discharge, cervical cancer, hearing and eyesight problems, bowel

\footnotetext{
* Correspondence: Deborah.Loxton@newcastle.edu.au

Research Centre for Generational Health and Ageing, School of Medicine and Public Health, University of Newcastle, Callaghan, New South Wales,
} Australia

(c) The Author(s). 2019 Open Access This article is distributed under the terms of the Creative Commons Attribution 4.0 International License (http://creativecommons.org/licenses/by/4.0/), which permits unrestricted use, distribution, and reproduction in any medium, provided you give appropriate credit to the original author(s) and the source, provide a link to the Creative Commons license, and indicate if changes were made. The Creative Commons Public Domain Dedication waiver (http://creativecommons.org/publicdomain/zero/1.0/) applies to the data made available in this article, unless otherwise stated. problems [1], chronic disease [2], and chronic pain [2,3] have mental health issues, including depression [4-6] anxiety $[4,7,8]$, suicidal ideation [2], and post-traumatic stress disorder $[8,9]$.

Globally, reported prevalence rates of IPV vary from 0.98 to $70.9 \%$ [3]. Research has demonstrated that prevalence rates differ depending on a number of methodological and cultural differences. Factors which affect IPV prevalence rates include the demographics of the sample (such as age and cultural background) $[10,11]$, the source of the sample 
(such as a clinical setting or nationally representative sample) $[12,13]$, the method (such as interviews or surveys) [14], and questions used to attain the information (such as asking participants to identify 'violent' experiences or specific behaviours) [15].

While methodological differences might explain some of this variation, one potential explanation that has received little attention is the consistency with which an individual might report IPV over time. Longitudinal research has demonstrated that participants do not consistently report abuse and experiences of adversity over time, with problems in consistency of self-reporting identified for experiences of physical abuse [16], sexual abuse [16, 17], potentially traumatic events [18], and negative life events [19]. Although there is evidence that experiences of abuse and adversity are not consistently reported over time, there is a paucity of available evidence regarding the consistency of reporting experiences of IPV over time.

The aim of this study is to investigate the consistency of self-report IPV involving a partner or spouse. The primary purpose is to identify and describe women who consistently reported IPV over 17 years, consistently reported later onset of IPV, consistently reported never experiencing IPV, and women who were inconsistent in their reports of IPV. Differences in the health status of women according to consistency of IPV reporting will also be investigated.

\section{Methods}

\section{Sample}

The current study examined IPV consistency using data collected from the 1946-51 cohort of the Australian Longitudinal Study on Women's Health (ALSWH). The ALSWH cohorts have been described in detail elsewhere [20]. Briefly, women were randomly selected from the Medicare (National Health Insurance) database, (which covers all Australian citizens and permanent residents), with women from rural and remote areas intentionally oversampled at twice the rate as other women. The 1946-51 cohort were recruited via mailed surveys in $1996(n=13,715)$ and have completed follow-up surveys every 3 years since 1998. Comparisons between women of the same age in the 1996 Census showed the women were broadly representative of Australian women of the same age with some overrepresentation of tertiary educated women [21]. This study is approved by the Human Research Ethics Committees of the Universities of Newcastle and Queensland. Women were included in the current study if they had responded to the first survey in 1996 and at least two of the five subsequent surveys between 2004 and 2016.

\section{Measures}

All variables were self-reported and were asked at each survey, unless otherwise indicated.
Consistency of self-report of IPV was evaluated by responses to the question, 'Have you ever been in violent relationship with a partner/spouse?' This question was first asked at Survey 1 in $1996(n=13,714)$ and at follow-up surveys conducted in 2004 (Survey 4, $n=10$, 905), 2007 (Survey 5, $n=10,638$ ), 2010 (Survey 6, $n=10$, 011), 2013 (Survey 7, $n=9151$ ), and 2016 (Survey 8, $n=$ 8622). An affirmative response to this question was used to indicate IPV.

To determine consistency of IPV reporting over time, data on IPV were required from participants for at least three of the six surveys. Responses were classified as 'Consistent IPV' (i.e. IPV was reported at all surveys answered e.g. YYY, YYYYYY), 'Consistent later IPV' (i.e. did not experience IPV at earlier surveys but did at later surveys e.g. NYY, NNY, NNNNYY), 'Consistent never IPV' (i.e. never experienced IPV at any survey e.g. NNN, NNNNNN) and 'Inconsistent IPV' (i.e. provided a negative response after an affirmative response for IPV). This group was further split into "Mainly IPV" (i.e. reported IPV at all but one subsequent survey e.g. YNY, YYN, YYYNYY), 'Mainly no IPV' (i.e. reported IPV at one survey followed by no IPV for all other surveys e.g. YNN, NYN, YNNNNN) and 'Mixed IPV responses' (i.e. inconsistently reported IPV across time e.g. YNYN, YYN, YNNY, YNNNYN).

Area of residence was classified using the Accessibility/ Remoteness Index of Australia (ARIA+), which measures accessibility to services from a person's home [22] and was grouped into four categories (major city, inner regional, outer regional and remote/very remote). In 1996, women were asked to indicate the highest qualification they had completed. Responses were categorised as 'Less than Year 12', 'Year 12 or equivalent', 'Trade, Certificate or Diploma', or 'University degree or higher degree'. At each survey, relationship status was classed as 'Married', 'De facto' (cohabiting), 'Separated', 'Divorced', 'Widowed' or 'Single'. Change in relationship status over time was classified in terms of being separated or divorced: never separated or divorced, remained separated or divorced, became partnered at a later survey, or became separated or divorced at a later survey.

At each survey, women were asked how stressed they felt about their relationship with their partner or spouse. Responses of 'Very stressed' or 'Extremely stressed' were used to indicate high partner stress. If participants indicated that they were very or extremely stressed about their relationship with their partner for at least half of their completed surveys, they were categorised as being highly stressed about their partner over time.

An indicator for experiencing financial stress is measured at each survey with the question "How do you manage on the income you have available?" Response options of 'Impossible' and 'Difficult all the time' were 
used to indicate high financial stress, while responses of 'Easy', 'Not too bad' and 'Difficult some of the time' suggested low financial stress. Participants were classified as being highly stressed about income over time if they indicated that they had high financial stress for at least half of their completed surveys.

\section{Statistical analyses}

Demographic and health characteristics were compared for consistent and inconsistent reporters of IPV, with selected characteristics compared for baseline (1996) and over time. Multinomial logistic regression was used to determine the strength of associations between demographic and health characteristics of the women and their longitudinal reporting of IPV. These models simultaneously estimate the odds ratios and their 95\% confidence intervals for the explanatory variables for each IPV group, relative to the Consistent IPV group (i.e. always reported IPV consistently). A sensitivity analysis was done with the multinomial logistic regression repeated for women who responded to the IPV questions at all surveys. All analyses were conducted in SAS version 9.4 [23] and statistical significance was set at 0.05 .

\section{Results}

Of the 10,966 women who answered IPV questions over six surveys, 2530 (23.1\%) reported IPV at least once. Nearly two-thirds $(65.1 \%)$ of women responded to all six surveys, and a further $26.4 \%$ responded to four or five surveys (Table 1). Consistent responses to IPV questions were given by 9610 women $(87.6 \%)$, with 827 women consistently reporting IPV at all surveys (7.5\%; Consistent IPV), 347 women consistently reporting IPV at later surveys (3.2\%; Consistent later IPV) and 8436 consistently reporting they had never experienced IPV (76.9\%; Consistent never IPV). Inconsistent responses were provided by 1356 women (12.4\%), with 258 women reporting IPV at all but one survey (2.4\%; Mainly IPV), 587 women reporting no IPV at all but one survey (5.4\%; Mainly no IPV), and 511 women reporting mixed responses over time (4.7\%; Mixed IPV). There were 2721 women who were not eligible for inclusion (ie. did not answer the IPV question at Survey 1 and at least two subsequent surveys), with most of these women (69\%) responding to Survey 1 only. Women who were ineligible for this analysis reported a higher prevalence of IPV at Survey $1(21.4 \%)$ than those who were eligible (15.0\%).

Women who reported 'Consistent never IPV' or 'Mainly no IPV' were very similar in qualifications (Table 2). The 'Consistent never IPV' group of women were most likely to be married in 1996, least likely to be separated or divorced at any time, were least stressed about their partner and were least likely to be stressed about their income in 1996 or later. Women who reported 'Consistent IPV' or 'Mainly IPV' were most likely to be separated or divorced in 1996, to stay that way over time and to have financial difficulty. Women who had 'Mixed IPV' responses across surveys were similar to those women who consistently reported IPV (Consistent IPV) in regards to health and demographic variables.

There was little evidence to suggest that area of residence or highest qualification were associated with patterns of IPV reporting over time (Table 3). Women who remained separated/divorced or became separated/divorced were more likely to report no IPV at all surveys (Consistent never IPV) or no IPV at most surveys (Mainly no IPV) than women in the other groups. Women who were stressed about their partner over time were less likely to report no IPV at all surveys (Consistent never IPV), while women who were stressed about income over time were less likely to report IPV at all surveys (Consistent IPV) or mostly no IPV (Consistent no IPV) across surveys. Compared to women who completed six surveys, women who completed fewer surveys were more likely to report IPV consistently at later surveys (Consistent later IPV) or more likely to report IPV at most surveys (Mainly IPV).

The characteristics of women by consistency of reporting IPV over time remained largely the same when only women who responded to all six surveys were examined (Table 4).

\section{Discussion}

This study aimed to examine the consistency of selfreported IPV in a longitudinal cohort survey setting.

Table 1 Proportion of women consistently and inconsistently reporting IPV over time $(N=10,966)$

\begin{tabular}{|c|c|c|c|c|c|c|c|}
\hline & \multicolumn{3}{|c|}{ Consistent IPV reporting } & \multicolumn{3}{|c|}{ Inconsistent IPV reporting } & \multirow[b]{2}{*}{ All women } \\
\hline & Consistent IPV & Consistent later IPV & Consistent never IPV & Mainly IPV & $\begin{array}{l}\text { Mainly } \\
\text { no IPV }\end{array}$ & $\begin{array}{l}\text { Mixed } \\
\text { IPV }\end{array}$ & \\
\hline Number of times IPV question answered & $N=827$ & $N=347$ & $N=8436$ & $N=258$ & $N=587$ & $N=511$ & $N=10,966$ \\
\hline $3(n=936)$ & 13.0 & 15.6 & 7.9 & 15.9 & 12.3 & 0.0 & 8.5 \\
\hline $4(n=1173)$ & 14.2 & 17.3 & 9.9 & 11.2 & 14.3 & 9.2 & 10.7 \\
\hline $5(n=1722)$ & 15.7 & 19.0 & 15.2 & 20.9 & 16.5 & 17.8 & 15.7 \\
\hline $6(n=7135)$ & 57.1 & 48.1 & 67.0 & 51.9 & 56.9 & 73.0 & 65.1 \\
\hline
\end{tabular}

Column percentages 
Table 2 Characteristics of women according to consistency of reporting IPV over time

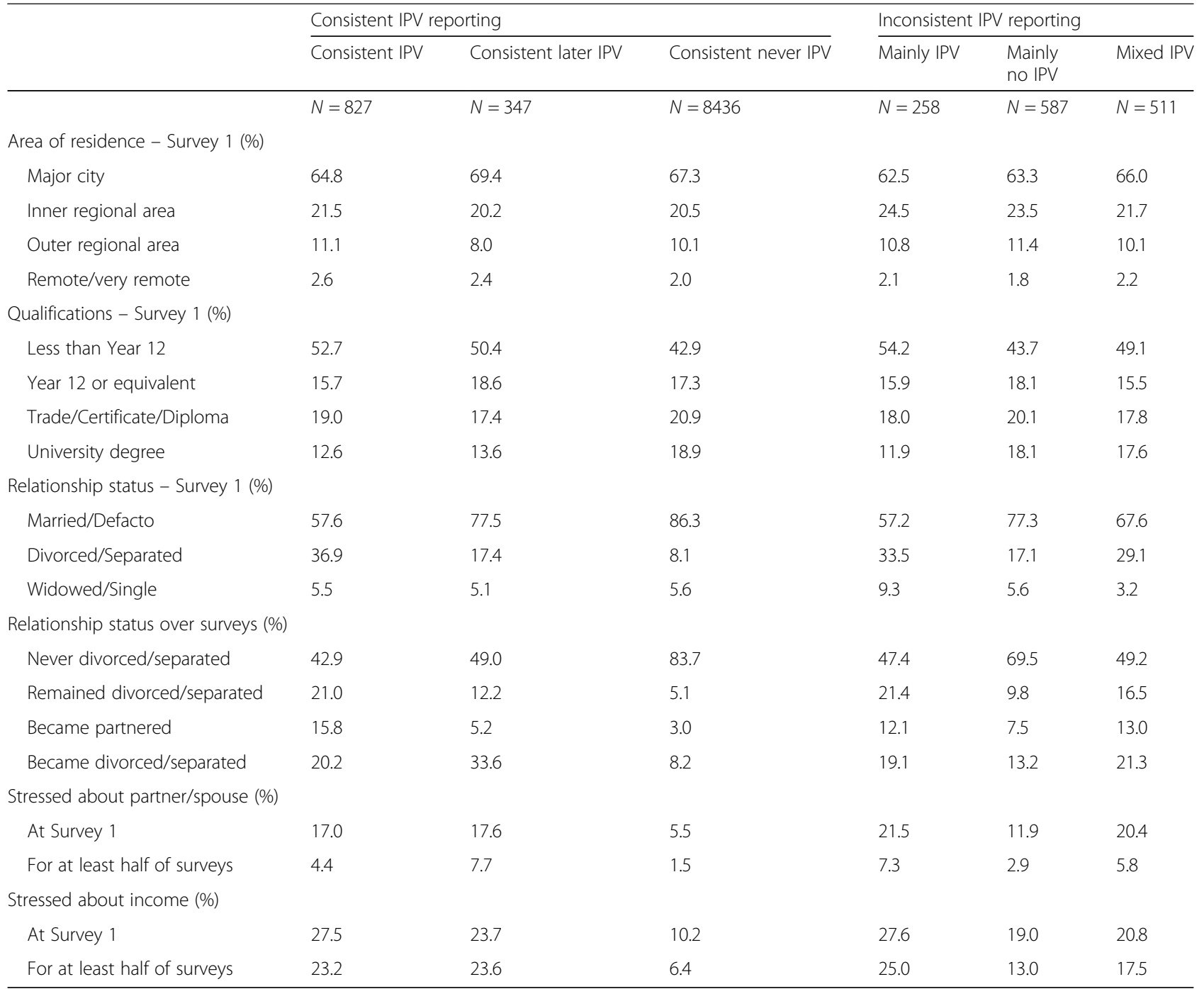

Percentages weighted for intentional oversampling of women living in rural and remote areas of Australia

Across six surveys, $76.9 \%$ of women consistently reported never experiencing IPV across any survey that they completed, $10.7 \%$ of women consistently reported IPV across all surveys that they completed, with the remaining $12.4 \%$ of women inconsistently reporting IPV across surveys. Among the inconsistent IPV responders, two-thirds were consistent most of the time, with $19 \%$ of women mainly reporting IPV across surveys, $43 \%$ of women mainly reporting no IPV, and $38 \%$ of women ( $4.7 \%$ of the total sample) providing mixed IPV responses across surveys. These results suggest that a cross-sectional study may illicit disproportionate false positive and false negative reports of IPV, and that longitudinal data capture is more likely to provide an accurate representation of the population prevalence of IPV. Understanding the factors that influence IPV responding is imperative to the collection of accurate data, which are used to inform prevention and intervention policies.
More than half of the women who indicated that they had experienced IPV at one point in time later said they had never had this experience. These findings build on past research that found similar issues with consistency in regard to self-report of traumatic and abuse events where the perpetrator was not specified [16-18]. The findings suggest that, at least for single item IPV measures, there is a considerable margin for error in ascertaining the lifetime prevalence of IPV. The nature of this error requires further exploration.

There were systematic demographic and health differences between those who responded consistently and those who did not. Women who always reported IPV were similar to women who mainly reported IPV on demographic and health measures, while women who consistently reported never experiencing IPV were similar to women who mainly reported never experiencing IPV. This becomes problematic at the cross-sectional 
Table 3 Characteristics of women by consistency of reporting IPV over time for women who responded to at least three surveys $(N=10,881)^{a}$

\begin{tabular}{|c|c|c|c|c|c|}
\hline Characteristics & $\begin{array}{l}\text { Consistent later IPV } \\
(\mathrm{OR}, 95 \% \mathrm{Cl})\end{array}$ & $\begin{array}{l}\text { Consistent never IPV } \\
(\mathrm{OR}, 95 \% \mathrm{Cl})\end{array}$ & $\begin{array}{l}\text { Mainly IPV } \\
(\mathrm{OR}, 95 \% \mathrm{Cl})\end{array}$ & $\begin{array}{l}\text { Mainly no IPV } \\
(\mathrm{OR}, 95 \% \mathrm{Cl})\end{array}$ & $\begin{array}{l}\text { Mixed IPV } \\
(\mathrm{OR}, 95 \% \mathrm{Cl})\end{array}$ \\
\hline \multicolumn{6}{|l|}{ Area of residence } \\
\hline Major city & 1 & 1 & 1 & 1 & 1 \\
\hline Inner regional area & $0.85(0.64,1.15)$ & $0.82(0.68,0.97)$ & $1.17(0.84,1.63)$ & $0.93(0.72,1.20)$ & $0.92(0.71,1.19)$ \\
\hline Outer regional area & $0.66(0.46,0.96)$ & $0.82(0.67,1.02)$ & $0.98(0.65,1.47)$ & $1.01(0.75,1.36)$ & $0.84(0.61,1.16)$ \\
\hline Remote/very remote & $0.76(0.43,1.33)$ & $0.61(0.44,0.85)$ & $0.87(0.45,1.68)$ & $0.59(0.35,0.99)$ & $0.85(0.51,1.41)$ \\
\hline \multicolumn{6}{|l|}{ Highest qualification } \\
\hline Less than Year 12 & 1 & 1 & 1 & 1 & 1 \\
\hline Year 12 or equivalent & $1.36(0.96,1.94)$ & $1.39(1.11,1.73)$ & $0.99(0.65,1.50)$ & $1.21(0.88,1.65)$ & $1.17(0.85,1.61)$ \\
\hline Trade/Certificate/Diploma & $0.91(0.64,1.29)$ & $1.10(0.90,1.34)$ & $0.94(0.65,1.37)$ & $1.00(0.75,1.34)$ & $0.80(0.59,1.08)$ \\
\hline University & $1.08(0.71,1.65)$ & $1.68(1.32,2.15)$ & $0.90(0.56,1.46)$ & $1.44(1.03,2.02)$ & $1.11(0.78,1.58)$ \\
\hline \multicolumn{6}{|l|}{ Relationship status over time } \\
\hline Remained not separated/divorced & 1 & 1 & 1 & 1 & 1 \\
\hline Remained separated/divorced & $0.58(0.39,0.87)$ & $0.14(0.11,0.18)$ & $0.86(0.57,1.29)$ & $0.29(0.20,0.42)$ & $0.88(0.63,1.21)$ \\
\hline Became not separated/divorced & $0.38(0.23,0.64)$ & $0.10(0.08,0.13)$ & $0.81(0.51,1.28)$ & $0.29(0.19,0.43)$ & $0.75(0.52,1.08)$ \\
\hline Became separated/divorced & $1.28(0.95,1.73)$ & $0.20(0.16,0.24)$ & $0.87(0.60,1.26)$ & $0.41(0.30,0.55)$ & $0.90(0.67,1.20)$ \\
\hline \multicolumn{6}{|c|}{ Stressed about partner for at least half of surveys } \\
\hline No & 1 & 1 & 1 & 1 & 1 \\
\hline Yes & $1.65(0.98,2.79)$ & $0.47(0.31,0.70)$ & $1.32(0.70,2.49)$ & $0.86(0.48,1.53)$ & $1.34(0.78,2.32)$ \\
\hline \multicolumn{6}{|c|}{ Stressed about income for at least half of surveys } \\
\hline No & 1 & 1 & 1 & 1 & 1 \\
\hline Yes & $0.88(0.64,1.21)$ & $0.37(0.30,0.45)$ & $0.94(0.67,1.34)$ & $0.63(0.47,0.85)$ & $0.84(0.62,1.12)$ \\
\hline \multicolumn{6}{|l|}{ Number of surveys } \\
\hline 6 surveys & 1 & 1 & 1 & 1 & 1 \\
\hline 5 surveys & $1.48(1.04,2.10)$ & $1.00(0.81,1.25)$ & $1.47(1.01,2.14)$ & $1.22(0.90,1.65)$ & $0.89(0.66,1.21)$ \\
\hline 3 or 4 surveys & $1.41(1.05,1.90)$ & $0.69(0.57,0.83)$ & $1.11(0.79,1.55)$ & $1.14(0.88,1.47)$ & $0.26(0.18,0.36)$ \\
\hline
\end{tabular}

${ }^{\text {aMultinomial logistic regression with Consistent IPV as reference group }(n=821)}$

level when examining demographic and health correlates of IPV, due to the risk of IPV misclassification. Given the similarities between groups, it is possible that those who mainly reported IPV represented women who might have provided a single false negative response, thus contributing to under-reporting; while those who mainly reported never experiencing IPV provided a single false positive response, thus contributing to overreporting.

Past research has indicated that women may underreport IPV due to fear of retribution and feelings of shame or embarrassment [24], which reflects intentional under-reporting. Unintentional under-reporting could occur due to a lack of recognition that experiences constituted violence $[25,26]$. Ackerman found that women unintentionally over-reported IPV when behavioural items were interpreted literally [27]. For example, a 'slap' might be recorded where the experience was undertaken in jest and not in any way harmful or intimidating. Yet, this scenario would seem unlikely in the current study, where the single item asked only about the experience of living in a 'violent relationship'. Ackerman did not find evidence for intentional over-reporting among women [27], although some literature proposes that women may over-report to gain favourable outcomes in divorce proceedings [28-30]. Potential gains of providing a false positive response in a confidential survey environment are unknown, as are the motivations. In fact, past research has indicated that women are more likely to respond affirmatively to sensitive questions within a confidential questionnaire than in other settings [14]. It would be useful for future research to determine the degree to which inconsistent responses reflect false positive or false negative responses.

The major limitation of the current paper is the single item used to assess the presence of IPV, which is likely to lead to under-reporting when compared to asking women behavioural questions [31]. However, some screening 
Table 4 Characteristics of women by consistentcy of reporting IPV for women who responded to all six surveys $(N=7100)^{a}$

\begin{tabular}{|c|c|c|c|c|c|}
\hline Characteristics & $\begin{array}{l}\text { Consistent later IPV } \\
(\mathrm{OR}, 95 \% \mathrm{Cl})\end{array}$ & $\begin{array}{l}\text { Consistent never IPV } \\
(\mathrm{OR}, 95 \% \mathrm{Cl})\end{array}$ & $\begin{array}{l}\text { Mainly IPV } \\
(\mathrm{OR}, 95 \% \mathrm{Cl})\end{array}$ & $\begin{array}{l}\text { Mainly no IPV } \\
(\mathrm{OR}, 95 \% \mathrm{Cl})\end{array}$ & $\begin{array}{l}\text { Mixed IPV } \\
(\mathrm{OR}, 95 \% \mathrm{Cl})\end{array}$ \\
\hline \multicolumn{6}{|l|}{ Area of residence [ref: Major city] } \\
\hline Inner regional area & $0.87(0.57,1.31)$ & $0.86(0.68,1.08)$ & $1.37(0.87,2.17)$ & $0.86(0.62,1.20)$ & $0.98(0.71,1.34)$ \\
\hline Outer regional area & $0.77(0.45,1.29)$ & $0.92(0.69,1.22)$ & $1.27(0.72,2.22)$ & $1.12(0.76,1.67)$ & $0.92(0.62,1.36)$ \\
\hline Remote/very remote & $1.12(0.53,2.38)$ & $0.64(0.41,1.01)$ & $0.98(0.37,2.55)$ & $0.64(0.32,1.29)$ & $0.92(0.49,1.73)$ \\
\hline \multicolumn{6}{|c|}{ Highest qualification [ref: Less than year 12] } \\
\hline Year 12 or equivalent & $1.24(0.74,2.07)$ & $1.29(0.97,1.73)$ & $1.19(0.68,2.08)$ & $1.04(0.68,1.59)$ & $1.24(0.84,1.83)$ \\
\hline Trade/Certificate/Diploma & $1.00(0.63,1.59)$ & $1.07(0.84,1.38)$ & $1.17(0.72,1.90)$ & $1.03(0.72,1.49)$ & $0.86(0.60,1.24)$ \\
\hline University & $1.28(0.76,2.18)$ & $1.71(1.26,2.31)$ & $0.96(0.51,1.82)$ & $1.54(1.01,2.34)$ & $1.12(0.74,1.70)$ \\
\hline \multicolumn{6}{|c|}{ Relationship over time [ref: Remained not separated/divorced] } \\
\hline Remained separated/divorced & $0.57(0.32,1.03)$ & $0.13(0.10,0.17)$ & $0.63(0.35,1.15)$ & $0.25(0.15,0.42)$ & $0.72(0.48,1.08)$ \\
\hline Became not separated/divorced & $0.42(0.20,0.87)$ & $0.11(0.08,0.15)$ & $0.94(0.51,1.74)$ & $0.31(0.18,0.53)$ & $0.87(0.56,1.34)$ \\
\hline Became separated/divorced & $1.25(0.82,1.90)$ & $0.18(0.14,0.23)$ & $0.80(0.48,1.32)$ & $0.36(0.24,0.54)$ & $0.88(0.62,1.25)$ \\
\hline \multicolumn{6}{|c|}{ Stressed about partner for at least half of surveys [ref: No] } \\
\hline Yes & $3.12(1.27,7.68)$ & $0.70(0.34,1.44)$ & $2.43(0.89,6.68)$ & $1.24(0.46,3.37)$ & $1.57(0.66,3.72)$ \\
\hline \multicolumn{6}{|c|}{ Stressed about income for at least half of surveys [ref: No] } \\
\hline Yes & $0.57(0.33,0.98)$ & $0.31(0.23,0.41)$ & $1.36(0.85,2.19)$ & $0.59(0.38,0.91)$ & $0.87(0.60,1.25)$ \\
\hline
\end{tabular}

${ }^{\mathrm{a}}$ Multinomial logistic regression with Consistent IPV as reference group $(n=470)$

programs operate on a single question about violence in the home [32-34], so it is important to understand what happens when single questions are asked which require recognition of violence. A further limitation is the age of the sample, all of whom were born 1946-51. It is possible that there are idiosyncrasies particular to women of this age that might not apply to women born in different eras. It should also be noted that women with a tertiary level of education were overrepresented. ALSWH participants from the 1946-51 cohort who were ineligible for the current study were more likely to have reported IPV at baseline than those who were eligible. However, these women were not eligible for the current study, so their propensity for consistent or inconsistent reporting has not been examined. Most of these women took part in the first survey only and do not generally represent those women likely to continue participating in a longitudinal study. One should remain cognisant that the prevalence of IPV may be under-estimated in a longitudinal setting due to participants who may not actively participate in later surveys. With regard to generalisability, the results directly relate to Australian women born 1946-51, within the constraints mentioned above. However, given the timeframe over which IPV has been measured, it would be reasonable to suggest that the results pertain to women in middle to early old age. The results point to the need for future research to establish the existence and nature of reporting IPV among younger women and women in other cultural settings. Finally, we note that this analysis was focused on women, with more research required to understand how other members of the population might respond to items that ask about IPV.

Women who respond inconsistently on a single occasion could be categorised with groups that reflect the majority of their responses (i.e. Mainly IPV with the Consistent IPV group; Mainly never IPV with the Consistent never IPV group). However, categorising women who respond inconsistently on more than one occasion is problematic. More research is required to understand the factors that cause women to respond in a contradictory manner to questions that ask about IPV.

\section{Conclusion}

Our study demonstrates the advantage of longitudinal monitoring of IPV. Relying on a single crosssectional survey may potentially include around $12 \%$ false positive or false negative responses, which are only detectable when IPV is monitored over time. In many countries, the prevalence of IPV is measured at the national level using cross-sectional survey designs. Our results highlight the potential difficulty in obtaining an accurate point prevalence from single surveys, which may be used to inform policy. Nevertheless, it is encouraging that around $88 \%$ of women were very consistent when reporting IPV. Even though it is a sensitive topic, confidential longitudinal surveys can obtain a consistent measure of IPV.

\section{Abbreviations}

ALSWH: Australian Longitudinal Study on Women's Health; IPV: Intimate partner violence 


\section{Acknowledgements}

The research on which this paper is based was conducted as part of the Australian Longitudinal Study on Women's Health by the University of Newcastle, NSW, and the University of Queensland. We are grateful to the women who completed the surveys. Researchers at the Research Centre for Generational Health and Ageing at the University of Newcastle are members of the Hunter Medical Research Institute.

\section{Authors' contributions}

DL contributed to the conception, design, interpretation of results, and drafting and critical revision of the manuscript. JP contributed to the conception, design, statistical analysis, interpretation of results, and drafting and critical revision of the manuscript. NT and $\mathrm{MH}$ contributed to the design of the work, interpretation of data, and drafting and critical revision of the manuscript. PF contributed to the statistical analysis and interpretation of results, and drafting and critical revision of the manuscript. All authors approved the final version of the manuscript for publication.

\section{Funding}

This work was supported by the Australian Government Department of Health, which has funded the Australian Longitudinal Study on Women's Health since 1996. The funding body did not have a role in the design of this study, data collection, data analysis, data interpretation or preparation of the manuscript.

\section{Availability of data and materials}

Data are available upon request. The process for accessing the data is documented on the Australian Longitudinal Study on Women's Health website [http://www.alswh.org.au/how-to-access-the-data/alswh-data].

\section{Ethics approval and consent to participate}

This study is approved by the Human Research Ethics Committees of the Universities of Newcastle (H-076-0795) and Queensland (2004000224). Informed written consent was obtained from all participants of the Australian Longitudinal Study on Women's Health.

\section{Consent for publication}

Not applicable.

\section{Competing interests}

The authors declare that they have no competing interests.

\section{Received: 4 February 2019 Accepted: 12 September 2019} Published online: 29 October 2019

\section{References}

1. Loxton D, Schofield M, Hussain R, Mishra G. History of domestic violence and physical health in mid-life. Violence Against Women. 2006;12(8):715-31.

2. Ellsberg M, Jansen HA, Heise L, Watts $\mathrm{CH}$, Garcia-Moreno C. Intimate partner violence and women's physical and mental health in the WHO multicountry study on women's health and domestic violence: an observational study. Lancet (London, England). 2008:371(9619):1165-72.

3. Dillon G, Hussain R, Loxton D, Rahman S. Mental and physical health and intimate partner violence against women: a review of the literature. Int J Family Med. 2012;2013:15.

4. Carlson BE, McNutt LA, Choi DY. Childhood and adult abuse among women in primary health care: effects on mental health. J Interpers Violence. 2003; 18(8):924-41.

5. Taft AJ, Watson LF. Depression and termination of pregnancy (induced abortion) in a national cohort of young Australian women: the confounding effect of women's experience of violence. BMC Public Health. 2008;8(1):75

6. Beydoun HA, Beydoun MA, Kaufman JS, Lo B, Zonderman AB. Intimate partner violence against adult women and its association with major depressive disorder, depressive symptoms and postpartum depression: a systematic review and meta-analysis. Soc Sci Med. 2012:75(6):959-75.

7. Sato-DiLorenzo A, Sharps PW. Dangerous intimate partner relationships and women's mental health and health behaviors. Issues Mental Health Nurs. 2007;28(8):837-48.

8. Robertiello G. Common mental health correlates of domestic violence. Brief Treat Crisis Interv. 2006;6(2):111-21.
9. Krause ED, Kaltman S, Goodman LA, Dutton MA. Avoidant coping and PTSD symptoms related to domestic violence exposure: a longitudinal study. J Trauma Stress. 2008;21(1):83-90.

10. Rennison C, Rand MR. Nonlethal intimate partner violence against women: a comparison of three age cohorts. Violence Against Women. 2003;9(12):1417-28

11. Garcia-Moreno C, Henrica, A.F.M.J., Ellsberg, M., Heise, L. Prevalence of intimate partner violence: findings from the WHO multi-country study on women's health and domestic violence. Lancet 2006;368(9543):1260-1269.

12. Abbott J, Johnson R, Koziol-McLain J, Lowenstein SR. Domestic violence against women. Incidence and prevalence in an emergency department population. Jama. 1995;273(22):1763-7.

13. Loxton D, Dolja-Gore $X$, Anderson AE, Townsend N. Intimate partner violence adversely impacts health over 16 years and across generations: a longitudinal cohort study. PLoS One. 2017:12(6):e0178138.

14. Tourangeau R, Smith TW. Asking sensitive questions: the impact of data collection mode, question format, and question context. Public Opin Q. 1996;60(2):275-304.

15. Devries KM, Mak JY, Bacchus $\sqcup$, Child JC, Falder G, Petzold M, et al. Intimate partner violence and incident depressive symptoms and suicide attempts: a systematic review of longitudinal studies. PLoS Med. 2013;10(5):e1001439.

16. Pachana NA, Brilleman SL, Dobson AJ. Reporting of life events over time: methodological issues in a longitudinal sample of women. Psychol Assess. 2011;23(1):277-81

17. Langeland W, Smit JH, Merckelbach H, de Vries G, Hoogendoorn AW, Draijer $\mathrm{N}$. Inconsistent retrospective self-reports of childhood sexual abuse and their correlates in the general population. Soc Psychiatry Psychiatr Epidemiol. 2015:50(4):603-12.

18. Hepp U, Gamma A, Milos G, Eich D, Ajdacic-Gross V, Rossler W, et al. Inconsistency in reporting potentially traumatic events. Br J Psychiatry. 2006;188:278-83.

19. Ayalon L. Retrospective reports of negative early life events over a 4-year period: a test of measurement invariance and response consistency. J Gerontol Series B. 2015:72(5):901-12.

20. Lee C, Dobson AJ, Brown WJ, Bryson L, Byles J, Warner-Smith P, et al. Cohort profile: the Australian longitudinal study on Women's health. Int J Epidemiol. 2005;34(5):987-91.

21. Brown WJ, Dobson AJ, Bryson L, Byles JE. Women's health Australia: on the progress of the main cohort studies. J Women's Health Gender-Based Med. 1999:8(5):681-8.

22. GISCA. About ARIA+ (Accessibility/Remoteness Index of Australia) North Terrace: University of Adelaide; 2010 [Available from: http://gisca.adelaide. edu.au/projects/category/about_aria.html.

23. SAS Institute Inc. SAS/STAT User's Guide, Version 8. Cary: SAS Institute Inc: 1999

24. Birdsey E, Snowball L. Reporting violence to police: a survey of victims attending domestic violence services. Sydney: NSW Bureau of Crime Statistics and Research; 2013

25. Loxton D, Townsend, N., Cavenagh, D., Green L. Measuring domestic violence in longitudinal research. Department of Social Services; 2017

26. Evans M, Gregory A, Feder G, Howarth E, Hegarty K. "Even 'Daily' is not enough": how well do we measure domestic violence and abuse?-a think-aloud study of a commonly used self-report scale. Violence Vict. 2016;31(1):3-26.

27. Ackerman JM. Over-reporting intimate partner violence in Australian survey research. Br J Criminol. 2016;56(4):646-67.

28. Shaffer M, Bala N. Wife abuse, Child custody and access in Canada. J Emot Abus. 2003:3(3-4):253-75.

29. Johnston JR, Campbell LEG. Parent-child relationships in domestic violence families disputing custody. Fam Court Rev. 1993;31(3):282-98.

30. Bertrand LD, Paetsch JJ. Spousal Violence in Custody and Access Disputes: Recommendations for Reform; 2018. p. 14-5.

31. Devries KM, Mak JY, Garcia-Moreno C, Petzold M, Child JC, Falder G, et al. Global health. The global prevalence of intimate partner violence against women. Science. 2013;340(6140):1527-8

32. Peralta RL, Fleming MF. Screening for intimate partner violence in a primary care setting: the validity of "feeling safe at home" and prevalence results. J Am Board Family Pract. 2003:16(6):525-32.

33. McIntyre LM, Butterfield MI, Nanda K, Parsey K, Stechuchak KM, McChesney AW, et al. Validation of a trauma questionnaire in veteran women. J Gen Intern Med. 1999;14(3):186-9. 
34. Sagrestano LM, Rodriguez AC, Carroll D, Bieniarz A, Greenberg A, Castro L, et al. A comparison of standardized measures of psychosocial variables with single-item screening measures used in an urban obstetric clinic. J Obstet Gynecol Neonatal Nurs. 2006;31(2):147-55

\section{Publisher's Note}

Springer Nature remains neutral with regard to jurisdictional claims in published maps and institutional affiliations.

Ready to submit your research? Choose BMC and benefit from:

- fast, convenient online submission

- thorough peer review by experienced researchers in your field

- rapid publication on acceptance

- support for research data, including large and complex data types

- gold Open Access which fosters wider collaboration and increased citations

- maximum visibility for your research: over $100 \mathrm{M}$ website views per year

At BMC, research is always in progress.

Learn more biomedcentral.com/submissions 